Check for updates

Cite this: RSC Adv., 2018, 8, 31881

Received 13th July 2018

Accepted 29th August 2018

DOI: 10.1039/c8ra05991h

rsc.li/rsc-advances

\title{
Synthesis and characterization of new polyimides from diphenylpyrene dianhydride and ortho methyl substituted diamines
}

\author{
R. Sulub-Sulub, M. I. Loría-Bastarrachea, J. L. Santiago-García (D) and M. Aguilar- \\ Vega (iD *
}

\begin{abstract}
Three new polyimides were synthesized via one-step polycondensation from 3,8-diphenylpyrene-1,2,6,7tetracarboxylic dianhydride (DPPD) with two diamines with ortho methyl substitution (MBDAM and HFI) and one diamine without ortho substituents (BAPHF). The effect of diamine structure in DPPD based polyimides' physical, thermal, mechanical and gas transport properties has been studied. The polyimide structure was confirmed by FTIR and ${ }^{1} \mathrm{H}$ NMR. All polymers show high thermal stability with decomposition temperatures above $493{ }^{\circ} \mathrm{C}$, and glass transition temperatures above $336{ }^{\circ} \mathrm{C}$. Changes in packing density of polyimide membranes were assessed by wide angle $\mathrm{X}$-ray diffraction and correlated to fractional free volume FFV. Polyimides based on rigid DPPD dianhydride exhibited an improved gas permeability and selectivity when ortho methyl substituents are present in the diamine used for polyimide synthesis. DPPD-MBDAM polyimide showed the best gas productivity values with 565 barrer $\mathrm{CO}_{2}$ permeability and a selectivity of 16 for $\mathrm{CO}_{2} / \mathrm{CH}_{4}$.
\end{abstract}

\section{Introduction}

Aromatic polyimides continue to be the subject of extensive research in the field of membrane technology, particularly for gas separation, due to their high separation efficiency, excellent thermal stability, chemical resistance and mechanical properties..$^{1-3}$ However, there still are some challenges in the development of new materials with high gas separation performance. For instance, several strategies based on structure-property relationships have been evaluated, such as the polymerization of monomers with bulky pendant groups which offer the possibility to achieve high free volume polymers. ${ }^{4}$

The most commonly used dianhydride monomers in the preparation of polyimides for gas separation membranes are $4,4^{\prime}$ (hexafluoroisopropylidene)diphthalic anhydride (6FDA), pyromellitic dianhydride (PMDA) and 4,4'-oxidiphthalic anhydride (ODPA). ${ }^{5-10}$ Nevertheless, the synthesis of new dianhydrides is a subject of considerable current interest since they allow the design and synthesis of novel polyimides for gas separation membranes. In this regard, Ma et al. reported two novel carbocyclic pseudo-Tröger's derived dianhydrides, which were employed to prepare soluble polyimides with an excellent gas separation performance, exceeding the upper bound for $\mathrm{O}_{2} / \mathrm{N}_{2}$, and $\mathrm{H}_{2} / \mathrm{CH}_{4}{ }^{11} \mathrm{Ma}$ and Pinnau, reported the synthesis of polyimides synthetized with two new ethanoanthracene-based

Unidad de Materiales, Centro de Investigación Científica de Yucatán, A. C., Calle 43 No. 130, Chuburná de Hidalgo, C. P. 97200, Mérida, Yucatán, México. E-mail: mjav@cicy.mx dianhydrides that exhibited good performance for gas separation in particular for $\mathrm{H}_{2} / \mathrm{CH}_{4}$ and $\mathrm{O}_{2} / \mathrm{N}_{2}$ separation. ${ }^{12}$ Santiago-García et al. reported the synthesis of three polyimides based on 3,8diphenylpyrene-1,2,6,7-tetracarboxylic dianhydride (DPPD). DPPD with a rigid structure and bulky groups showed to be an excellent candidate for polyimides synthesis for gas separation membranes due to an excellent combination of permeability and selectivity. ${ }^{13}$ However, in order to understand the full potential of this pyrene dianhydride structure for performing gas separation, further studies on DPPD polyimides are necessary to develop new polyimides, that allow us to understand how the use this dianhydride DPPD or similar structures could enhance polyimide membrane properties and separation performance.

It was reported that better performing polymers for membrane application would be obtained by increasing polymer chain rigidity but maintaining the gas diffusivity by increasing interchain separation., ${ }^{4,14}$ The use methyl groups have been reported as molecular spacers, increasing interchain separation which will allow increases in gas permeability by enhancing fractional free volume. Tanaka et al., synthetized polyimides and reported an increases in fractional free volume and permeability, with ortho methyl substitution on the diamine phenyl ring. ${ }^{15}$ Naguel et al. have reported about the effects ortho methyl groups on polyimide and poly(amide-imide) on free volume and gas permeation. The introduction of ortho methyl groups increases the average $d$-spacing and the gas permeability. ${ }^{16}$

Therefore, in this work, we report the synthesis of three novel aromatic polyimides based on the DPPD dianhydride using a diortho methyl substituted diamine, 4-4'-methylenbis(2,6- 
dimethyl-aniline) (MBDAM), a mono methyl substituted diamine, 5,5'-(hexafluoroisopropylidene)-di-o-toluidine) (HFI), and a non-methyl substituted diamine, 2,2-bis[4-(4-aminophenoxy)phenyl] hexafluoropropane (BAPHF). Hence, we are trying to elucidate the effect of the use of aromatic diamines with and without ortho substituted methyl groups linked to the imide bond. The differences in polyimide solubility, mechanical properties under tension, thermal properties, physical properties and gas separation performance are determined and the changes due to the ortho methyl substitution discussed.

\section{Experimental}

\section{Materials}

Solvents and reagents were purchased from Sigma Aldrich. Nitrobenzene (NB), pyridine (Py), benzoic acid, 4-4'methylenbis(2,6-dimethyl-aniline) (MBDAM) and 5,5'-(hexafluoroisopropylidene)-di-o-toluidine) (HFI) were used as received. 2,2-Bis[4-(4-aminophenoxy)phenyl] hexafluoropropane (BAPHF) was purified by crystallization in a solution of ethanol/water (70/30 v/v). 3,8-Diphenylpyrene1,2,6,7-tetracarboxylic dianhydride (DPPD) was synthesized through a multistep synthetic route according to the procedure that has been previously reported and crystallized in nitrobenzene before use. ${ }^{13}$

\section{Polymer synthesis}

The polyimides were synthesized via polycondensation reaction from the base dianhydride DPPD and three aromatic diamines (MBDAM, HFI, BAPHF), using the one-step method as shown in Fig. 1. In a typical synthesis, DPPD-MBDAM was prepared according to the following procedure. $1 \mathrm{mmol}$ MBDAM was dissolved in $6 \mathrm{~mL}$ of nitrobenzene in a $50 \mathrm{~mL}$ three-neck flask equipped with a nitrogen inlet/outlet, and a mechanical stirrer. $1 \mathrm{mmol}$ of DPPD was added and the mixture was heated to $80{ }^{\circ} \mathrm{C}$. Then, $2 \mathrm{mmol}$ of pyridine were added and the solution was maintained at that temperature for $1 \mathrm{~h}$. The reaction solution was heated to $120^{\circ} \mathrm{C}$ and $2 \mathrm{mmol}$ of benzoic acid were added. The solution was heated to $200{ }^{\circ} \mathrm{C}$ for $24 \mathrm{~h}$. After cooling, the viscous solution was poured into ethanol to obtain a yellow fibrous polymer. This material was filtered off, washed with ethanol and dried under vacuum at $200{ }^{\circ} \mathrm{C}$ for $24 \mathrm{~h}$. The yield of this polyimide was $93 \%$. Polyimides DPPD-HFI and DPPD-BAPHF were synthesized by a similar procedure.

\section{Film preparation}

Dense films were prepared by a casting method using the following procedure. Each polyimide was dissolved in nitrobenzene a $4 \%(\mathrm{w} / \mathrm{v})$. The polyimide solution was filtered through a $200 \mu \mathrm{m}$ Teflon syringe filter and then poured onto an aluminum ring placed on a glass plate. Subsequently, the solvent was evaporated at $80{ }^{\circ} \mathrm{C}$ for $12 \mathrm{~h}$. The film was dried under vacuum at $230{ }^{\circ} \mathrm{C}$ for $48 \mathrm{~h}$. The complete removal of solvent was confirmed using thermogravimetric analysis.

\section{Characterization}

Solubility was determined by dissolving $5 \mathrm{mg}$ of polymer in $1 \mathrm{~mL}$ of solvent at room temperature. ${ }^{1} \mathrm{H}$ NMR spectra were recorded on a Varian VNMRS $600 \mathrm{MHz}$ spectrometer using $\mathrm{CDCl}_{3}$ as a solvent. Fourier transform infrared (FTIR) spectra were recorded on a Nicolet 8700 Thermo Scientific FTIR spectrometer using an ATR accessory.

Inherent viscosities $\left(\eta_{\text {inh }}\right)$ were measured using an Ubbelohde viscometer at a polyimide concentration of $0.5 \mathrm{~g} \mathrm{dL}^{-1}$ in DMF at $30{ }^{\circ} \mathrm{C}$. For MBDAM $\eta_{\text {inh }}$ was determined in nitrobenzene at $50{ }^{\circ} \mathrm{C}$. Thermogravimetric analyses (TGA) were performed on a thermobalance TGA 7 under nitrogen atmosphere at a heating rate of $10{ }^{\circ} \mathrm{C} \mathrm{min}^{-1}$. Differential scanning calorimetry (DSC) measurements were carried out using a MettlerToledo DSC 1 Star System at a heating rate of $10{ }^{\circ} \mathrm{C} \mathrm{min}{ }^{-1}$ under nitrogen atmosphere. Mechanical properties under uniaxial tension were determined on a Shimadzu AGS-X universal testing machine with a $100 \mathrm{~N}$ load cell at a crosshead speed of $1 \mathrm{~mm} \mathrm{~min}{ }^{-1}$. Films with dimensions of $0.5 \mathrm{~cm}$ long $\times 2 \mathrm{~cm}$ wide and thicknesses of $100 \mu \mathrm{m}$ (DPPD-MBDAM and DPPD-HFI) and $60 \mu \mathrm{m}$ (DPPD-BAPHF) were used. At least five individual samples were tested for each polyimide film.

X-ray diffraction (XRD) was conducted on a Bruker D8 Advance diffractometer with $\mathrm{CuK} \alpha$ radiation (wavelength $\lambda_{\mathrm{Cu}}=$ $1.542 \AA$ ), in range of $5^{\circ}$ to $60^{\circ} 2 \theta$. The average $d$-spacing was calculated using Bragg's law:

$$
d=\frac{n \lambda}{2 \sin \theta}
$$

where $\theta$ of the broad peak maximum. Polyimide density ( $\rho$ ) was measured in a density gradient column (Techne Corporation) with calcium nitrate solutions at $23{ }^{\circ} \mathrm{C}$. The fractional free volume (FFV) was calculated from the density data using the following relation:

$$
\mathrm{FFV}=\frac{V_{0}-1.3 V_{\mathrm{w}}}{V_{0}}
$$

where $V$ is specific volume of the polymer (i.e., the inverse of the polymer density) and $V_{\mathrm{w}}$ is the van der Waals volume, which was estimated by the group contribution method outlined by Zhao et $a .^{17}$

Pure gas permeability coefficients $(P)$ were determined using a constant volume permeation cell of the type described elsewhere, ${ }^{18}$ according to the following equation:

$$
P=\frac{273}{76} \frac{V l}{A T p_{0}} \frac{\mathrm{d} p}{\mathrm{~d} t}
$$

where $A$ and $l$ are, the effective area and the thickness of the film, $T$ is the temperature of the measurement $(308.15 \mathrm{~K}), V$ is the constant volume of the permeation cell, $p_{0}$ is the pressure of the feed gas in the upstream and $\mathrm{d} p / \mathrm{d} t$ is the gas pressure increase with time under steady state conditions measured in the permeation cell. $P$ is expressed in Barrer $\left[1\right.$ barrer $=10^{-10}$ $\mathrm{cm}^{3}$ (STP) $\mathrm{cm} \mathrm{cm}^{-2} \mathrm{~s}^{-1} \mathrm{~cm} \mathrm{Hg}^{-1}$. The apparent diffusion coefficient, $D$, was obtained by the time lag method using the relation: 

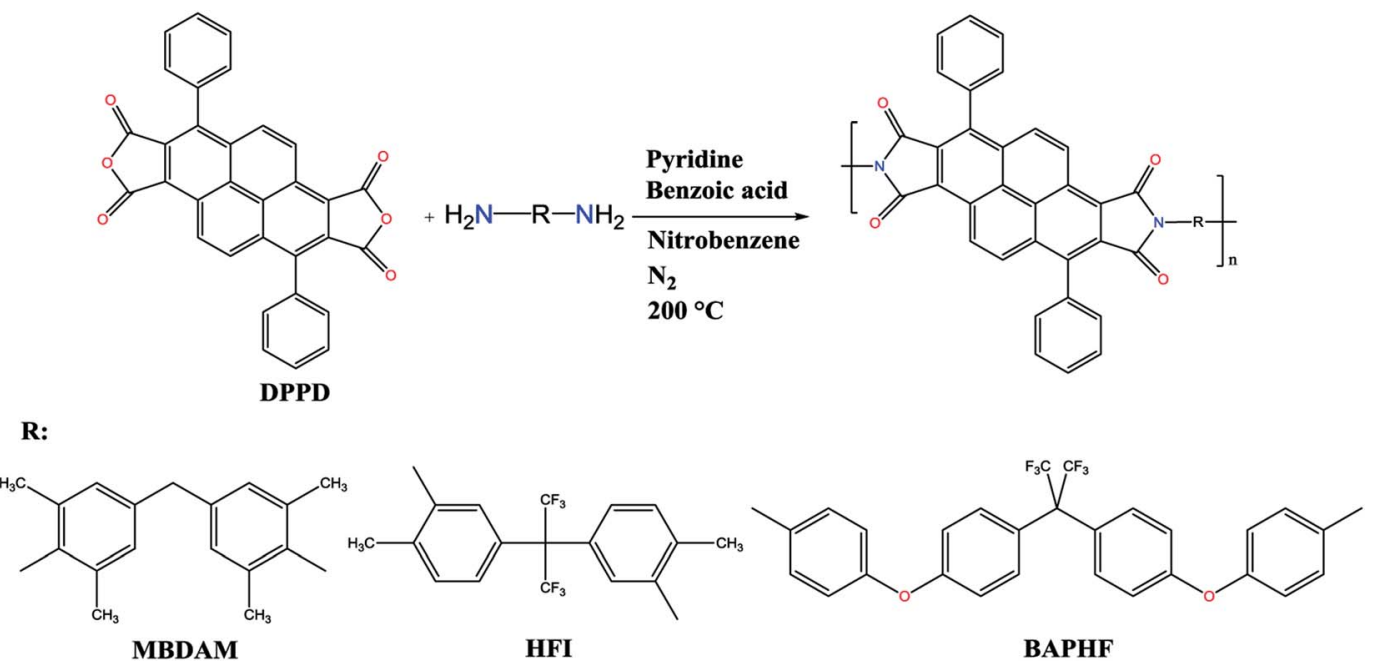

Fig. 1 Schematic synthesis of DPPD based polyimides.

$$
D=\frac{l^{2}}{6 \theta}
$$

here $l$ is the film thickness and $\theta$ is the time lag. The apparent solubility coefficient, $S$, was obtained using the relationship

$$
S=\frac{P}{D}
$$

\section{Result and discussion}

Three new polyimides were synthesized by one-step hightemperature polycondensation reaction between the previously synthesized 3,8-diphenylpyrene-1,2,6,7-tetracarboxylic dianhydride (DPPD) and commercial diamines, using nitrobenzene as solvent, and pyridine and benzoic acid as shown in Fig. 1. Fig. 2 shows the ATR-FTIR spectra of the three polyimides studied. Characteristic absorption bands of polyimides appeared at 1770 and $1710 \mathrm{~cm}^{-1}(\mathrm{C}=\mathrm{O}$ asymmetrical and symmetrical stretching), $1370 \mathrm{~cm}^{-1}$ (C-N stretching). For substituted polyimides, typical aliphatic $\mathrm{C}-\mathrm{H}$ absorption bands at 2940-2860 $\mathrm{cm}^{-1}$ were also observed from those with $-\mathrm{CH}_{3}$ substitution (DPPD-MBDAM and DPPD-HFI). Also, DPPDBAPHF spectrum shows characteristic bands 1170 and $1207 \mathrm{~cm}^{-1}$ ( $-\mathrm{CF}_{3}$ symmetrical and asymmetric stretching). The fully imidized structure is confirmed by the absence of absorption bands in $3300 \mathrm{~cm}^{-1}$ (C-N stretching) present in the non-cyclized structure of the corresponding poly(amic acid). DPPD-MBDAM, DPPD-HFI and DPPD-BAPHF polyimides were also characterized by ${ }^{1} \mathrm{H}-\mathrm{NMR}$ spectroscopy. As an example, Fig. 3 shows the ${ }^{1} \mathrm{H}-\mathrm{NMR}$ spectra of polyimide DPPD-HFI, in which all the protons in the structure are assigned. The signals assigned to the protons of methyl groups were detected at $2.19 \mathrm{ppm}$. The aromatic protons resonated in the region of 7.30-9.40 ppm. The spectra confirm the imidized structure, as indicated by the absence of poly(amic acid) protons.

Polyimides solubility was evaluated dissolving $5 \mathrm{mg}$ of polymer in $1 \mathrm{~mL}$ of solvent. All polyimides except DPPD-BAPHF were soluble in $\mathrm{CHCl}_{3}$ at ambient temperature and insoluble in DMSO, as shown in Table 1.

However, DPPD-HFI exhibited better solubility, in both polar aprotic solvents such as DMAc, DMF, DMSO and NMP and low boiling point solvents, $\mathrm{CHCl}_{3}$ and THF. Moreover, DPPD-BAPHF showed the lowest solubility since it is partially soluble in nitrobenzene on heating at the boiling point. Based on these differences in solubility, nitrobenzene was used for casting membranes in order to maintain the same thermal history. Also Table 1 shows the inherent viscosities $\left(\eta_{\text {inh }}\right)$ of DPPD based polyimides. $\eta_{\text {inh }}$ 's of DPPD polyimides were in the range of 0.32 $\mathrm{dL} \mathrm{g}^{-1}$ to $0.79 \mathrm{dL} \mathrm{g}^{-1}$, which are related to moderate to high molecular weight polymers similar to some structurally rigid polyimides reported in the literature. ${ }^{\mathbf{1 9 , 2 0}}$ In the case of DPPDBAPFH which is not soluble under the test conditions intrinsic viscosity was not determined.

\section{Thermal properties}

The thermal properties of the DPPD based polyimides were evaluated by TGA and DSC and the results are summarized in Table 2 . The glass transition temperature $\left(T_{\mathrm{g}}\right)$ of these polyimides was in the range of 336 to $369{ }^{\circ} \mathrm{C}$ and decreased in the

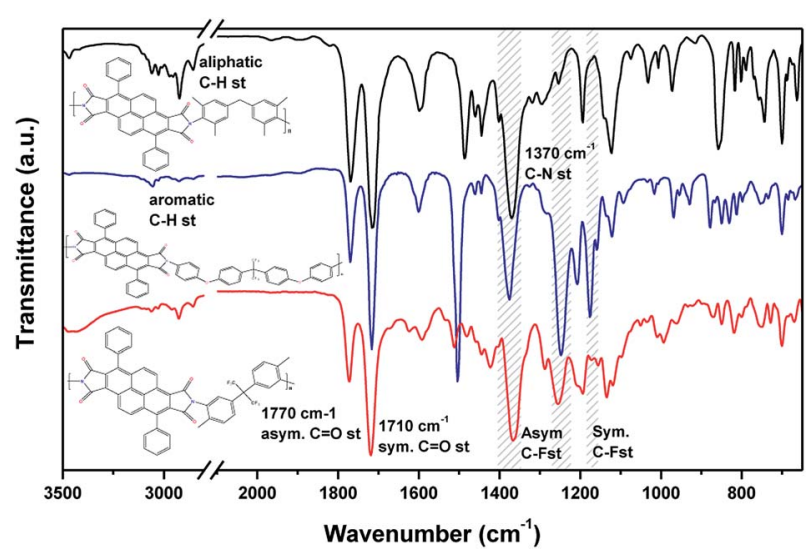

Fig. 2 FTIR spectra of polyimide films. 


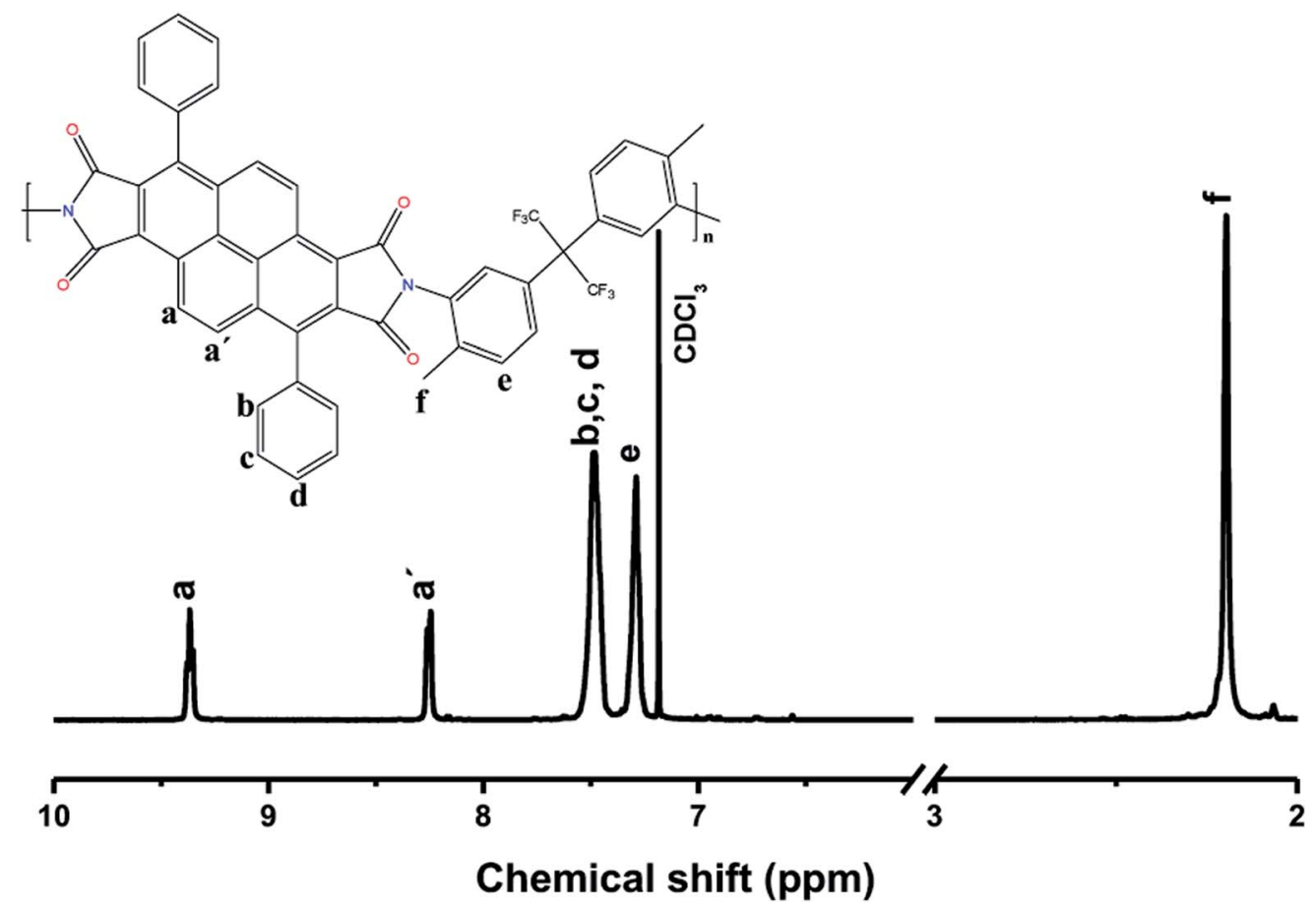

Fig. $3{ }^{1} \mathrm{H}$ NMR spectra of the polyimide DPPD-HFI.

Table 1 Solubility and viscosity of DPPD based polyimides

\begin{tabular}{|c|c|c|c|c|c|c|c|c|}
\hline Polyimide & \multicolumn{7}{|c|}{ Solubility } & $\eta_{\text {inh }}\left(\mathrm{dL} \mathrm{g}^{-1}\right)$ \\
\hline DPPD-HFI ${ }^{b}$ & + & + & + & + & + & - & + & 0.32 \\
\hline DPPD-BAPHF & - & - & - & - & - & - & \pm & - \\
\hline
\end{tabular}

${ }^{a} \eta_{\text {inh }}$ measured in nitrobenzene at $50{ }^{\circ} \mathrm{C} .{ }^{b} \eta_{\text {inh }}$ measured in DMF at $30^{\circ} \mathrm{C} .+$ : soluble; -: insoluble; ${ }^{*+}$ : soluble on heating at boiling point; \pm : partially soluble on heating at boiling point. NMP: 1-methyl-2-pyrrolidone; DMF: $N, N$-dimethylformamide; DMAC: $N, N$-dimethylacetamide; DMSO: dimethyl sulfoxide; THF: tetrahydrofuran; NB: nitrobenzene.

following order DPPD-MBDAM > DPPD-HFI > DPPD-BAPHF. The DPPD-MBDAM with two ortho methyl substitutions close to the $-\mathrm{C}-\mathrm{N}$ - link in the imide ring had the highest $T_{\mathrm{g}}$ value at $369{ }^{\circ} \mathrm{C}$, while DPPD-BAPHF without substituent in the ortho position of the BAPHF diamine phenyl bonded at the imide has the lowest $T_{\mathrm{g}}$ value at $338{ }^{\circ} \mathrm{C}$. It is well know that the glass transition is affected by the chain conformation (rigidity and linearity) and interchain interactions. ${ }^{2,21}$ The ortho methyl substituted DPPD-MBDAM and DPPD-HFI may restricts the

Table 2 Thermal properties of the DPPD based polyimides ${ }^{a}$

\begin{tabular}{llllll}
\hline Polymer & $T_{\mathrm{d}}\left({ }^{\circ} \mathrm{C}\right)$ & $T_{5}\left({ }^{\circ} \mathrm{C}\right)$ & $T_{10}\left({ }^{\circ} \mathrm{C}\right)$ & Char yield $^{b}(\%)$ & $T_{\mathrm{g}}$ \\
\hline DPPD-MBDAM & 546 & 567 & 605 & 71 & 369 \\
DPPD-HFI & 517 & 545 & 568 & 64 & 352 \\
DPPD-BAPFH & 515 & 526 & 548 & 63 & 338
\end{tabular}

${ }^{a} T_{\mathrm{d}}$ : degradation temperature measured in onset, $T_{5}$ y $T_{10}$ : degradation temperature at 5 y $10 \%$ weight loss, respectively. ${ }^{b}$ Measured at $800{ }^{\circ} \mathrm{C}$ in $\mathrm{N}_{2}$. rotation of the $\mathrm{C}-\mathrm{N}$ bond in the polyimide that results in a higher chain rigidity and increase the inter-chain interaction due the electro-donating nature of the $\mathrm{CH}_{3}$ group, which

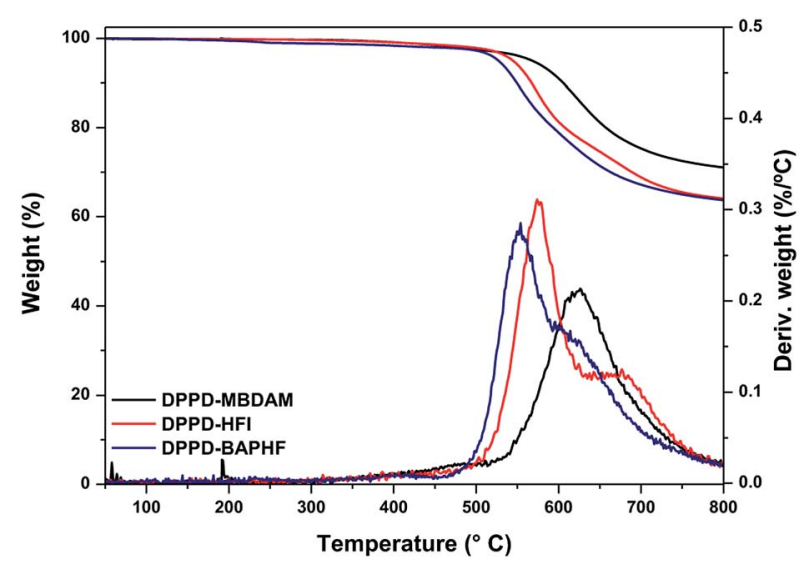

Fig. 4 TGA thermograms of the DPPD based polyimides. 
Table 3 Mechanical properties of DPPD based polyimide membranes

\begin{tabular}{lllr}
\hline Polymer & Young's modulus (GPa) & Tensile strength (MPa) & Elongation at break (\%) \\
\hline DPPD-MBDAM & $1.29 \pm 0.01$ & $62 \pm 6$ & $7.3 \pm 2$ \\
DPPD-HFI & $1.27 \pm 0.04$ & $42 \pm 2$ & $4 \pm 1$ \\
DPPD-BAPHF & $1.20 \pm 0.05$ & $53 \pm 5$ & $8 \pm 2$ \\
\hline
\end{tabular}

resulted in an increase in $T_{\mathrm{g} .}{ }^{2}$ Therefore, the presence of two $-\mathrm{CH}_{3}$ in the ortho phenyl position induces a $T_{\mathrm{g}}$ increase in DPPD-MBDAM as compared to DPPD-HFI. While DPPD-BAPHF showed the lowest $T_{\mathrm{g}}$ value due to a larger degree of conformational freedom attributed to the presence of the ether linkages in the main polymer chain. Thermal stability thermograms for DPPD-MBDAM, DPPD-HFI and DPPD-BAPHF are shown in Fig. 4 and thermal decomposition data are reported in Table 2. The $5 \%\left(T_{5}\right)$ and $10 \%\left(T_{10}\right)$ weight losses were found to occur at temperature ranges from 526 to $567{ }^{\circ} \mathrm{C}$ and 548 to $605{ }^{\circ} \mathrm{C}$ respectively. All polyimides show high thermal stability in nitrogen atmosphere, with a degradation temperature $\left(T_{\mathrm{d}}\right)$ above $515{ }^{\circ} \mathrm{C}$.

The high char yield of these polyimides was due to the high aromatic content of the polymers. Moreover, DTGA curves of DPPD-BAPHF and DPPD-HFI show two degradation steps under nitrogen. The first weight loss, around $500{ }^{\circ} \mathrm{C}$, is attributed to the $-\mathrm{CF}_{3}$ group degradation, whereas the second weight loss occurring around $600{ }^{\circ} \mathrm{C}$ could be attributed to main chain decomposition.

\section{Mechanical properties}

Table 3 show mechanical properties of DPPD based polyimides; they showed Young's modulus and tensile strengths in the range of 1.20-1.30 GPa and 42-62 MPa, respectively. The three polyimide films presented similar Young modules, around 1.2 GPa. DPPD-HFI, show the lowest elongation at break and tensile strength due to a lower inherent viscosity. DPPDMBDAM exhibited the highest tensile strength at $62 \mathrm{MPa}$ and tensile modulus $1.29 \mathrm{GPa}$. These mechanical properties are comparable to other highly aromatic polyimides previously reported in the literature..$^{20,22,23}$

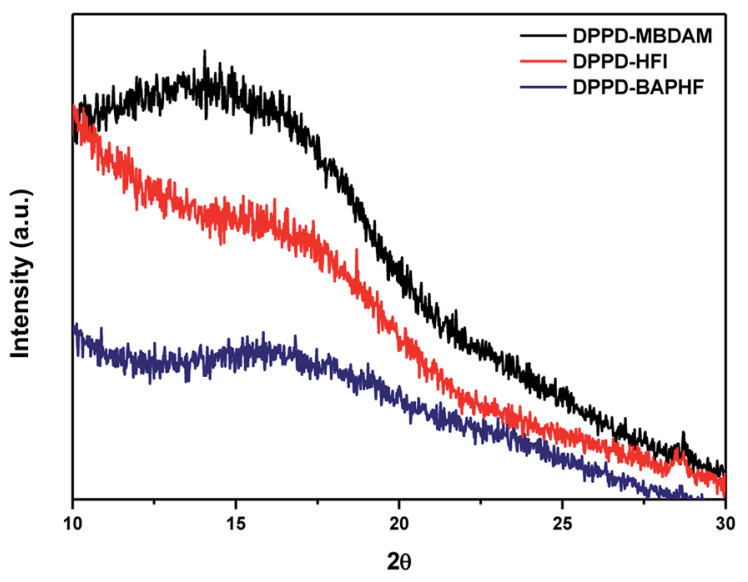

Fig. 5 X-ray diffraction pattern for DPPD based polyimides.
Fig. 5 shows X-ray diffraction (XRD) patterns for DPPD based polyimides. The resulting patterns revealed that all the polyimides are amorphous with broad peaks. The average interchain distances ( $d$-spacing) values were calculated from the position of the maximum in the broad X-ray diffraction pattern. $d$-spacing is often related to the average chain distance and packing density of polymer chains. ${ }^{24}$ X-ray diffraction pattern for DPPD-MBDAM shows a broader shoulder than DPPD-HFI and DPPD-BAPHF. The maximum of this shoulder corresponds to a $d$-spacing of $6.1 \AA(2 \theta=14.49)$. DPPD-HFI shows 2 maxima in the amorphous halo corresponding to a $5.33 \AA$ ( $2 \theta=$ $16.80)$ and $8.807 \AA d$-spacing $(2 \theta=10.01)$. While DPPD-BAPHF show one maxima with $d$-spacing at $5.21 \AA(2 \theta=16.80)$. The ortho substitution in MBDAM restricts the mobility of the polymer chains and increase the interchain distance, this effect can observed in the position and shape of the amorphous halo that agrees with the results found. Also, these results are in agreement with fractional free volume FFV values, as show in Table 4. According to the literature, polymers with larger $d$ spacing generally tend to have a larger $\mathrm{FFV}^{25} \mathrm{FFV}$ shows a decrease in the following order DPPD-MBDAM $>$ DPPD-HFI $>$ DPPD-BAPHF. For DPPD based polyimides containing methyl in the ortho position of the diamine the internal rotation around the imide bond is restricted between the phenyl ring and the imide which inhibits chain packing. As a result they present higher fractional free volume as in this case does DPPDMBDAM and DPPD-HFI as compared to DPPD-BAPHF.

\section{DPPD based polyimides gas transport properties}

Pure gas permeability coefficients, $P$, for $\mathrm{H}_{2}, \mathrm{He}, \mathrm{O}_{2}, \mathrm{~N}_{2}, \mathrm{CH}_{4}$ and $\mathrm{CO}_{2}$ and the ideal selectivity for important gas pairs $\mathrm{O}_{2} / \mathrm{N}_{2}$, $\mathrm{CO}_{2} / \mathrm{CH}_{4}$ and $\mathrm{CO}_{2} / \mathrm{N}_{2}$, are reported in Table 5 . The permeability coefficients order found is $\mathrm{CO}_{2}>\mathrm{H}_{2}>\mathrm{He}>\mathrm{O}_{2}>\mathrm{CH}_{4}>\mathrm{N}_{2}$, where $P$ of $\mathrm{N}_{2}(3.64 \AA)$ is lower than the one of $\mathrm{CH}_{4}(3.8 \AA)$, and $\mathrm{CO}_{2}(3.3$ $\AA)$ shows a $P$ higher than He $(2.6 \AA)$. This is attributed to the high FFV presented in DPPD polyimides and permeability is comparable to the values reported for other polyimides of high FFV., ${ }^{3,424}$ DPPD polyimides show excellent gas permeability coefficients for the six gases tested and moderate selectivities

Table 4 Physical properties of DPPD based polyimides

\begin{tabular}{lllll}
\hline Polymer & $d_{1}$ spacing $(\AA)$ & $\begin{array}{l}\text { Density } \\
\left(\mathrm{g} \mathrm{cm}^{-3}\right)\end{array}$ & $\begin{array}{l}V_{\mathrm{dw}} \\
\left(\mathrm{cm}^{3} \mathrm{~mol}^{-1}\right)\end{array}$ & FFV \\
\hline DPPD-MBDAM & 6.23 & 1.181 & 384.03 & 0.170 \\
DPPD-HFI & 5.31 & 1.30 & 405.96 & 0.164 \\
DPPD-BAPHF & 5.09 & 1.32 & 483.15 & 0.152
\end{tabular}


Table 5 Gas permeability coefficients and ideal selectivity at $2 \mathrm{~atm}$ and $35{ }^{\circ} \mathrm{C}$ for DPPD based polyimides ${ }^{a}$

\begin{tabular}{|c|c|c|c|c|c|c|c|c|c|}
\hline \multirow[b]{2}{*}{ Polymer } & \multicolumn{7}{|c|}{ Permeability (barrer) } & \multicolumn{2}{|c|}{ Selectivity $\left(\alpha_{\mathrm{A} / \mathrm{B}}\right)$} \\
\hline & $P_{\mathrm{He}}$ & $P_{\mathrm{H}_{2}}$ & $P_{\mathrm{O}_{2}}$ & $P_{\mathrm{N}_{2}}$ & $P_{\mathrm{CH}_{4}}$ & $P_{\mathrm{CO}_{2}}$ & $\alpha_{\mathrm{O}_{2} / \mathrm{N}_{2}}$ & $\alpha_{\mathrm{CO}_{2} / \mathrm{CH}_{4}}$ & $\alpha_{\mathrm{CO}_{2} / \mathrm{N}_{2}}$ \\
\hline DPPD-HFI & 174 & 257 & 50 & 14 & 14 & 286 & 3.5 & 20.4 & 20.4 \\
\hline DPPD-BAPFH & 87 & 113 & 20 & 5.34 & 5.74 & 129 & 3.7 & 22.4 & 24.2 \\
\hline
\end{tabular}

${ }^{a} 1$ barrer $=10^{-10} \mathrm{~cm}^{3}(\mathrm{STP}) \mathrm{cm} \mathrm{cm}^{-2} \mathrm{~s}^{-1} \mathrm{~cm} \mathrm{Hg}^{-1}$.

that follows the order DPPD-MBDAM > DPPD-HFI > DPPDBAPHF. This result is attributed to the presence of methyl groups in ortho-position nearby the $-\mathrm{C}-\mathrm{N}$ - imide bonds that lower the local mobility of the polyimide chains, which is reflected in an increase of gas permeability. ${ }^{\mathbf{1 3 , 2 1 , 2 6}}$ This increase in gas permeability is higher for the disubstituted methyl polyimides. For example, the presence of two $-\mathrm{CH}_{3}$ on MBDAM, leads to a difference between 2 and 6 times in gas permeability coefficients for the ratio $P_{(\mathbf{M B D A M})} / P_{(\mathbf{B A P H F})}$, which is higher for the most condensable gases $\mathrm{CO}_{2}$ and $\mathrm{CH}_{4}$. Moreover, the presence of one $-\mathrm{CH}_{3}$ on HFI, leads to a 2 fold increase in permeability for the ratio $P_{(\mathbf{H F I})} / P_{(\mathbf{B A P H F})}$. This effect is in agreement with previous reports, which indicate that the introduction of ortho methyl substituted groups in the diamine moieties can increase gas permeability coefficients but they follow the usual trade off since there is a decreased in selectivity. ${ }^{27,28}$

Apparent gas diffusion coefficients, $D$, determined from time lag and apparent gas solubility coefficient $S$, (calculated from $D$ and $P$ ), are presented in Table 6 . Also the values of diffusivity selectivity, $\alpha\left(D_{\mathrm{A}} / D_{\mathrm{B}}\right)$, and solubility selectivity. $\alpha\left(S_{\mathrm{A}} / S_{\mathrm{B}}\right)$, are included. Table 6 shows that the introduction of methyl groups into the ortho position of polyimides increase the diffusion and solubility coefficients for all gases. This increase is larger for polyimides with ortho methyl groups. For example, the diffusion coefficients for DPPD-MBDAM exhibited 2-3 times those found for DPPD-BAPHF and 1.2-1.5 times the solubility coefficient. DPPD-MBDAM presents 1.2-1.6 fold higher diffusion coefficient

Table 6 Apparent gas diffusion coefficients for DPPD based polyimides

\begin{tabular}{|c|c|c|c|c|c|c|c|}
\hline \multirow[b]{2}{*}{ Polymer } & \multicolumn{4}{|c|}{$D\left(10^{-8} \mathrm{~cm}^{2} \mathrm{~s}^{-1}\right)$} & \multicolumn{3}{|c|}{$\alpha\left(D_{\mathrm{A}} / D_{\mathrm{B}}\right)$} \\
\hline & $D_{\mathrm{O}_{2}}$ & $D_{\mathrm{N}_{2}}$ & $D_{\mathrm{CH}_{4}}$ & $D_{\mathrm{CO}_{2}}$ & $\alpha_{\mathrm{O}_{2} / \mathrm{N}_{2}}$ & $\alpha_{\mathrm{CO}_{2} / \mathrm{CH}_{4}}$ & $\alpha_{\mathrm{CO}_{2} / \mathrm{N}_{2}}$ \\
\hline DPPD-MBDAM & 28.3 & 9.2 & 3.4 & 15 & 3.1 & 4.5 & 1.7 \\
\hline DPPD-HFI & 23.0 & 7.5 & 2.1 & 11.6 & 3.1 & 5.5 & 1.5 \\
\hline \multirow[t]{2}{*}{ DPPD-BAPFH } & 10.8 & 3.5 & 1.1 & 6.4 & 3.1 & 5.9 & 1.8 \\
\hline & \multicolumn{4}{|c|}{$\begin{array}{l}S\left(10^{-2} \mathrm{~cm}^{3}(\mathrm{STP})\right. \\
\left.\mathrm{cm}^{-3} \mathrm{~cm} \mathrm{Hg}^{-1}\right)\end{array}$} & \multicolumn{3}{|c|}{$\alpha\left(S_{\mathrm{A}} / S_{\mathrm{B}}\right)$} \\
\hline Polymer & $S_{\mathrm{O}_{2}}$ & $S_{\mathrm{N}_{2}}$ & $S_{\mathrm{CH}_{4}}$ & $S_{\mathrm{CO}_{2}}$ & $\alpha_{\mathrm{O}_{2} / \mathrm{N}_{2}}$ & $\alpha_{\mathrm{CO}_{2} / \mathrm{CH}_{4}}$ & $\alpha_{\mathrm{CO}_{2} / \mathrm{N}_{2}}$ \\
\hline DPPD-MBDAM & 2.8 & 2.5 & 10.3 & 36.8 & 1.1 & 3.6 & 14.5 \\
\hline DPPD-HFI & 2.2 & 1.9 & 6.6 & 24.7 & 1.2 & 3.7 & 13.1 \\
\hline DPPD-BAPFH & 1.8 & 1.5 & 5.3 & 20.2 & 1.2 & 3.8 & 13.3 \\
\hline
\end{tabular}

and 1.5-2 solubility coefficient as compared to DPPD-HFI. Meanwhile, DPPD-HFI presents 2 fold higher diffusion coefficients and $\mathbf{1 . 2}$ fold higher solubility coefficients relative to DPPD-BAPHF. Moreover, Table 6 show that the increase in solubility of $S_{(\text {MBDAM })} / S_{(\text {HFI })}$ is higher than $S_{(\mathbf{H F I})} / S_{(\mathbf{B A P H F})}$; although in both cases the difference is the presence of one methyl group. This can be attributed to a decrease in solubility of the polyimides with the presences of $\mathrm{CF}_{3}$ groups.

Plasticization is a phenomenon that has significant practical implications in membrane for gas separation particularly for $\mathrm{CO}_{2}$ removal from natural gas. ${ }^{29,30}$ Plasticization often results in an increase in permeability and a loss in selectivity, particularly at high pressures. ${ }^{31}$ To determine any potential plasticization effects $f$ on DPPD-MBDAM, DPPD-HFI and DPPD-BAPHF membranes, pure gas $\mathrm{CO}_{2}$ and $\mathrm{CH}_{4}$ permeabilities were also measured at $35{ }^{\circ} \mathrm{C}$ from 2 to 15 atm (Fig. 6). As it is usually
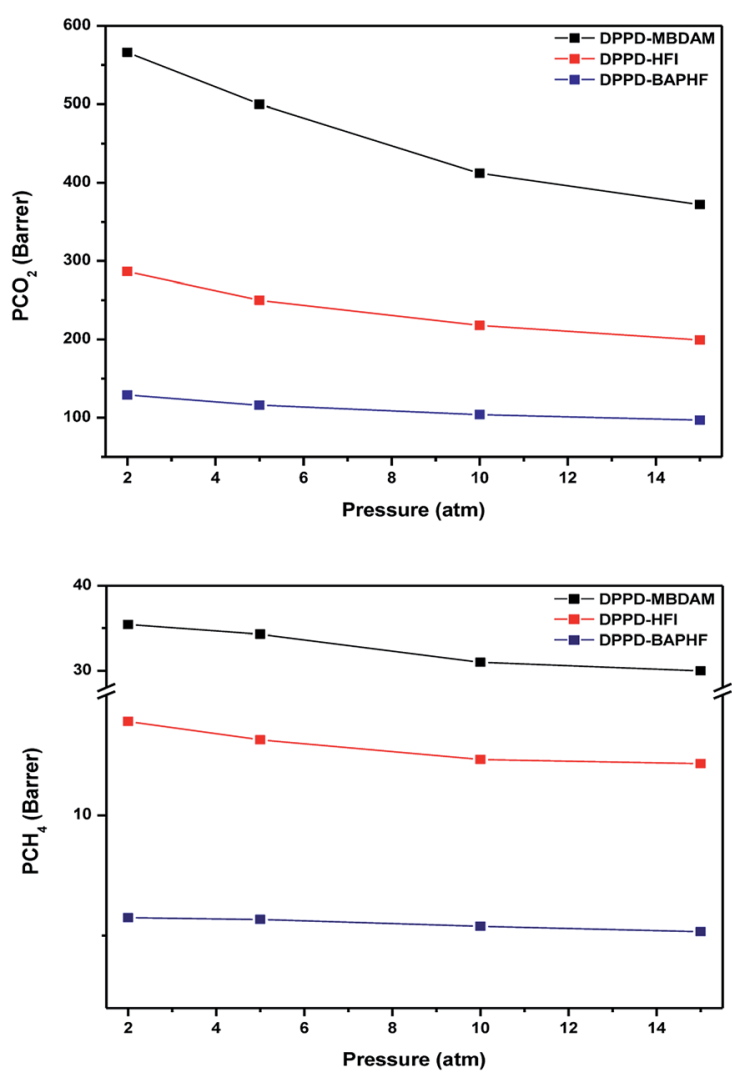

Fig. 6 Pressure dependence of pure $\mathrm{CO}_{2}$ and $\mathrm{CH}_{4}$ permeabilities for DPPD based polyimides. 

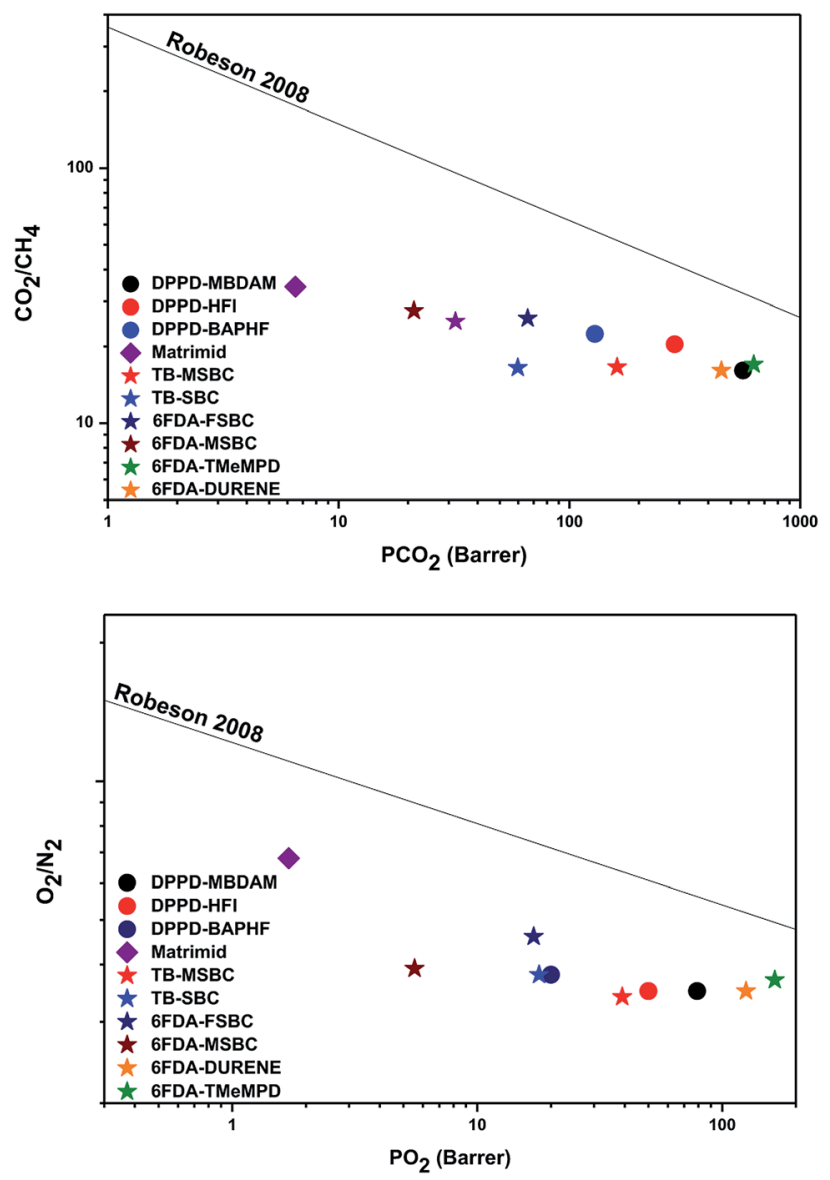

Fig. $7 \mathrm{CO}_{2} / \mathrm{CH}_{4}$ and $\mathrm{O}_{2} / \mathrm{N}_{2}$ productivities for DPPD based polyimides.

found in other polymers, pure $\mathrm{CO}_{2}$ and $\mathrm{CH}_{4}$ permeability coefficients of these polyimides decreased with increasing feed pressure up to 15 atm..$^{27,29,32,33}$ This preliminarily results indicates that DPPD-MBDAM, DPPD-HFI and DPPD-BAPHF membranes do not present plasticization up to a testing pressure of 15 atm.

Fig. 7 compares the productivities of the synthesized polyimides with Matrimid $\AA^{34}$ and polymers with different group substitutions recently published ${ }^{2,21}$ in a Robeson upper bound plot. ${ }^{35}$ From these plots it can be observed that for the pairs $\mathrm{CO}_{2} / \mathrm{CH}_{4}$ and $\mathrm{O}_{2} / \mathrm{N}_{2}$, the polyimides based on the DPPD dianhydride and the different diamines lead to permeabilityselectivity performance that is closer to the upper bound. DPPD based polyimides show a combination of high gas permeability coefficients and moderate selectivity. Therefore, the ortho methyl substituted diamines combined with DPPD leads to polyimides with a positive effect on the gas separation performance compared to polymers with different substitutions based in spirobichroman and Trögers base $\mathrm{e}^{2,21}$ and similar effect with 6FDA based polyimides.

\section{Conclusions}

Three new polyimides were synthesized from the dianhydride DPPD via one-step high-temperature polycondensation. These polyimides exhibited high thermal stability with decomposition temperatures above $505{ }^{\circ} \mathrm{C}$ and $T_{\mathrm{g}}$ above $338^{\circ} \mathrm{C}$. DPPD-MBDAM and DPPD-HFI polyimides show a relatively higher $d$-spacing and FFV due to the introduction of the methyl group into the ortho position of the diamine linked to de imide $(-\mathrm{C}-\mathrm{N})$ which decrease the chain packing and increases FFV and $d$-spacing. The ortho methyl substitution in the used diamine improves gas permeability coefficients with small decreases in gas pair selectivity for these polyimides. Moreover, the ortho methyl substitution and the number of ortho methyl groups present induce an increase in gas permeability with a decrease in selectivity. In particular, the DPPD-MBDAM shows the largest gas permeability with $P_{\mathrm{CO}_{2}}=565$ and selectivity $\mathrm{CO}_{2} / \mathrm{CH}_{4}=16$, with two ortho methyl substitutions close to the imide linkage.

\section{Conflicts of interest}

There are no conflicts of interest to declare.

\section{Acknowledgements}

Rita Sulub-Sulub gratefully acknowledges a scholarship from CONACYT (Mexico National Council for Science and Technology) under grant 389245. Partial funding by CONACYTSENER LENERSE II grant 254667. The authors are thankful to Dr Patricia Quintana and Dr Emmanuel Hernández for ${ }^{1} \mathrm{H}$ NMR analysis form The National Laboratory of Nano and Biomaterials (LANNBIO). Partial funding from grants FOMIX-Yucatán 2008-108160, CONACYT LAB-2009-01-123913 is acknowledged. The authors acknowledge the help of Dr Griselda Castruita for XRD analysis. We are grateful to Dr Humberto Vázquez-Torres for DSC analysis.

\section{References}

1 D. Bera, P. Bandyopadhyay, S. Ghosh and S. Banerjee, J. Membr. Sci., 2014, 453, 175.

2 C. Zhang, P. Li and B. Cao, J. Membr. Sci., 2017, 530, 176.

3 C. Álvarez, A. E. Lozano and J. G. de la Campa, J. Membr. Sci., 2016, 501, 191.

4 M. Calle, C. García, A. E. Lozano, J. G. de la Campa, J. de Abajo and C. Álvarez, J. Membr. Sci., 2013, 434, 121.

5 X. Ma, M. Abdulhamid, X. Miao and I. Pinnau, Macromolecules, 2017, 50, 9569.

6 C. Zhang, P. Li and B. Cao, J. Membr. Sci., 2017, 530, 176.

7 G. Qin, X. Cao, H. Wen, W. Wei and J. C. Diniz da Costa, Sep. Purif. Technol., 2017, 177, 129.

8 C. H. Jung and Y. M. Lee, Macromol. Res., 2008, 16, 555.

9 N. Alaslai, B. Ghanem, F. Alghunaimi, E. Litwiller and I. Pinnau, J. Membr. Sci., 2016, 505, 100.

10 M. A. Abdulhamid, X. Ma, X. Miao and I. Pinnau, Polymer, 2017, 130, 182.

11 X. Ma, M. A. Abdulhamid and I. Pinnau, Macromolecules, 2017, 50, 5850.

12 X. Ma and I. Pinnau, Macromolecules, 2018, 51, 1069.

13 J. L. Santiago-García, C. Álvarez, F. Sánchez and J. G. de la Campa, J. Membr. Sci., 2015, 476, 442. 
14 C. G. Bezzu, M. Carta, A. Tonkins, J. C. Jansen, P. Bernardo, F. Bazzarelli and N. B. McKeown, Adv. Mater., 2012, 24, 5930.

15 K. Tanaka, M. Okano, H. Toshino, H. Kita and K.-I. Okamoto, J. Polym. Sci., Part B: Polym. Phys., 1992, 30, 907.

16 C. Nagel, K. Günther-Schade, D. Fritsch, T. Strunskus and F. Faupel, Macromolecules, 2002, 35, 2071.

17 Y. H. Zhao, M. H. Abraham and A. M. Zissimos, J. Org. Chem., 2003, 68, 7368.

18 C. Carrera-Figueiras and M. Aguilar-Vega, J. Polym. Sci., Part B: Polym. Phys., 2005, 43, 2625.

19 Q. Zhang, S. Li, W. Li and S. Zhang, Polymer, 2007, 48, 6246. 20 Z. Ge, L. Fan and S. Yang, Eur. Polym. J., 2008, 44, 1252.

21 C. Zhang, J. Yan, Z. Tian, X. Liu, B. Cao and P. Li, Ind. Eng. Chem. Res., 2017, 56, 12783.

22 D.-J. Liaw, F.-C. Chang, M.-k. Leung, M.-Y. Chou and K. Muellen, Macromolecules, 2005, 38, 4024.

23 S. Y. Yang, Z. Y. Ge, D. X. Yin, J. G. Liu, Y. F. Li and L. Fan, J. Polym. Sci., Part A: Polym. Chem., 2004, 42, 4143.

$24 \mathrm{~W}$. Qiu, L. Xu, C.-C. Chen, D. R. Paul and W. J. Koros, Polymer, 2013, 54, 6226.
25 S.-H. Huang, C.-C. Hu, K.-R. Lee, D.-J. Liaw and J.-Y. Lai, Eur. Polym. J., 2006, 42, 140.

26 Y. Li, M. Ding and J. Xu, Macromol. Chem. Phys., 1997, 198, 2769.

27 N. Alaslai, B. Ghanem, F. Alghunaimi and I. Pinnau, Polymer, 2016, 91, 128.

28 X. Ma, O. Salinas, E. Litwiller and I. Pinnau, Macromolecules, 2013, 46, 9618.

29 R. Swaidan, B. Ghanem, E. Litwiller and I. Pinnau, Macromolecules, 2015, 48, 6553.

30 A. F. Ismail and W. Lorna, Sep. Purif. Technol., 2002, 27, 173.

31 D. F. Sanders, Z. P. Smith, R. Guo, L. M. Robeson, J. E. McGrath, D. R. Paul and B. D. Freeman, Polymer, 2013, 54, 4729.

32 J. R. Wiegand, Z. P. Smith, Q. Liu, C. T. Patterson, B. D. Freeman and R. Guo, J. Mater. Chem. A, 2014, 2, 13309. 33 J. Vaughn and W. J. Koros, Macromolecules, 2012, 45, 7036. 34 L. Shao, L. Liu, S.-X. Cheng, Y.-D. Huang and J. Ma, J. Membr. Sci., 2008, 312, 174.

35 L. M. Robeson, J. Membr. Sci., 2008, 320, 390. 